\title{
The Incidence of Amyotrophic Lateral Sclerosis in Ohio 2016-2018: The Ohio Population-Based ALS Registry
}

\author{
Angeline S. Andrew ${ }^{a}$ Erik P. Pioro ${ }^{b}$ Meifang $\mathrm{Li}^{c} \quad$ Xun Shic Jiang Guid \\ Elijah W. Stommel ${ }^{a}$ Tanya H. Butt ${ }^{a}$ Daniel Peipert ${ }^{a}$ Patricia Henegan ${ }^{a}$ \\ Maeve Tischbein ${ }^{a}$ Pamela Cazzollie John Novak ${ }^{f}$ Adam Quick $^{g}$ \\ K. Doug Pugar ${ }^{\text {h }}$ Komal Sawlani ${ }^{i}$ Bashar Katirji ${ }^{i}$ Todd A. Hayes $^{j}$ \\ D. Kevin Hortonk Paul Mehtak Walter G. Bradley'
}

\begin{abstract}
aDepartment of Neurology, Geisel School of Medicine, Dartmouth-Hitchcock Medical Center, Lebanon, NH, USA;
bSection of ALS and Related Disorders, Cleveland Clinic, Cleveland, OH, USA; 'Department of Geography, Dartmouth College, Hanover, NH, USA; dDepartment of Biomedical Data Science, Geisel School of Medicine at Dartmouth,

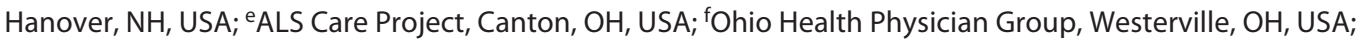
'Department of Neurology, Ohio State University Wexner Medical Center, Columbus, OH, USA; hayton Center for Neurological Disorders, Dayton, OH, USA; 'Department of Neurology, University Hospital Cleveland Medical Center, Cleveland, $\mathrm{OH}, \mathrm{USA} ;{ }^{j}$ Riverhills Neuroscience, Cincinnati, $\mathrm{OH}, \mathrm{USA} ;{ }^{\mathrm{k}}$ Centers for Disease Control and Prevention (CDC), Agency for Toxic Substances and Disease Registry (ATSDR), Atlanta, GA, USA; 'Department of Neurology, Miller School of Medicine, University of Miami, Miami, FL, USA
\end{abstract}

\section{Keywords}

Amyotrophic lateral sclerosis · Incidence · Ohio ·

Epidemiology $\cdot$ Hot spots

\begin{abstract}
Introduction: Amyotrophic lateral sclerosis (ALS) is a fatal, neuromuscular disease with no cure. ALS incidence rates have not been assessed specifically in Ohio, yet the state contains both metropolitan and rural areas with a variety of environmental factors that could contribute to disease etiology. We report the incidence of ALS in Ohio residents diagnosed from October 2016 through September 2018. Methods: We engaged practitioners from 9 Ohio sites to identify newly diagnosed ALS patients and to complete case report forms with demographic and clinical information. ALS was
\end{abstract}

karger@karger.com www.karger.com/ned

Karger $\stackrel{\text { ' }}{5}$

GOPEN ACCESS
(C) 2021 The Author(s)

Published by S. Karger AG, Basel

This is an Open Access article licensed under the Creative Commons Attribution-NonCommercial-4.0 International License (CC BY-NC) (http://www.karger.com/Services/OpenAccessLicense), applicable to the online version of the article only. Usage and distribution for commercial purposes requires written permission. diagnosed according to the Awaji criteria and classified as either definite, probable, or possible. We developed a method to estimate missing cases using a Poisson regression model to impute cases in counties with evidence of undercounting. Results: We identified 333 newly diagnosed ALS patients residing in Ohio during the 2-year index period and found incidence rates varied in the 88 state counties. After incorporating the estimated $27 \%$ of missing cases, the corrected crude annual incidence was 1.96/100,000 personyears, and the age- and gender-standardized incidence was $1.71 / 100,000$ person-years (standardized to the 2010 US census). Discussion/Conclusion: The estimated Ohio incidence of ALS is overall similar to that reported in other states in the USA. This study reveals a geospatial variation in incidence within the state, and areas with higher rates warrant future investigation.

(c) 2021 The Author(s)

Published by S. Karger AG, Basel
Correspondence to:

Walter G. Bradley, w.bradley@miami.edu 


\section{Introduction}

Amyotrophic lateral sclerosis (ALS) is a progressive, usually fatal neuromuscular disease without known cause or cure. The lifetime risk of developing ALS is about 1:400 [1]. Approximately $10 \%$ of cases are inherited (familial), and mutations in $30+$ genes have been identified in over two-thirds of these families [2]. For the remaining $90 \%$ of "sporadic" ALS cases, more than a dozen environmental/ lifestyle risk factors have been implicated [3], and variants in $40+$ genes have been found to increase the risk of ALS [4-8]. It is hypothesized that sporadic ALS is triggered by environmental/lifestyle factors interacting with predisposing genetic traits [9]. The multiplicity of such interactions led to ALS being identified as a multistep process similar to cancer $[10,11]$.

ALS, like most non-communicable diseases, is not a notifiable disease in the United States (US). In 2009, the National ALS Registry was established by Public Law No. 110-373 to collect data on ALS patients in the USA, describe the incidence and prevalence of ALS, examine environmental and occupational risk factors, and characterize the demographics of persons living with ALS [12]. The National ALS Registry has reported the prevalence of ALS in select states and metropolitan areas as well as estimated incidence. For example, the average age-adjusted annual incidence rate for New Jersey was 1.67 per 100,000 person-years in 2009-2011 [13]. Globally, ALS rates are greatest in regions with a high sociodemographic index (such as North America, Western Europe, and Australasia which comprise $49 \%$ of the global cases), but show considerable and unexplained geographic heterogeneity [14]. Part of this observed variation $[15,16]$ might be explained by an aging population. ALS incidence increases with age up to 75 years $[1,17]$, and the older the population, the longer it is exposed to harmful environmental factors (the "exposome").

Although Ohio was not one of the states originally included in the States and Metropolitan Areas projects led by the National ALS Registry [18], it presents an ideal opportunity to examine ALS epidemiology. Ohio has a welldeveloped network of medical centers and clinics experienced in treating ALS, diverse multiethnic/racial metropolitan areas, and rural populations with long histories of exposure to industrial and agricultural toxicants. Additionally, Lake Erie and many other Ohio water bodies have recurrent, cyanobacterial harmful algal blooms that are suggested to be risk factors for ALS [19-24].

We developed the population-based Ohio ALS Registry with the goals of determining the incidence of ALS in this state, assessing the demographic characteristics of patients, and searching for associations between ALS and environmental toxins/toxicants. We attempted to collect every newly diagnosed (incident) ALS patient in Ohio during a 2-year index period. This study describes the Ohio ALS Registry, its major demographic findings, and their interpretation. We also describe our developed method for estimating cases missed in recruiting for such registries.

\section{Materials and Methods}

Recruitment and Participation in the Ohio ALS Registry

Physicians in Ohio who frequently see ALS patients were identified with the assistance of several organizations including the Ohio Chapters of the ALS Association and the Muscular Dystrophy Association. Physicians were approached by mail and e-mail, informed about the Ohio ALS Registry, and invited either to refer newly diagnosed ALS patients to Dr. Pioro at the Cleveland Clinic for a research appointment or enroll patients directly. Participating physicians either obtained approval for the study from their local Institutional Review Board (IRB) or deferred to the Dartmouth-Hitchcock Medical Center IRB. Collaborating institutions received a small remuneration for each completed case report form. Although no geospatial information was available, ALS cases from Ohio Veterans Affairs (VA) Medical Centers were counted from within the VA Informatics and Computing Infrastructure firewall.

The Ohio ALS Registry sought to count every patient newly diagnosed with ALS living in Ohio during the 2-year period of October 1,2016, through September 30, 2018. The clinical base of the registry was the Section of ALS and Related Disorders, Cleveland Clinic, Cleveland, OH, USA, under the direction of Dr. Pioro. The other collaborating centers/organizations were Ohio Health Physician Group, Westerville, OH, USA; Ohio State University Wexner Medical Center, Columbus, OH, USA; Dayton Center for Neurological Disorders, Dayton, OH, USA; University Hospitals Cleveland Medical Center, Cleveland, OH, USA; Riverhills Neuroscience, Cincinnati, OH, USA; ALS Care Project, Canton, $\mathrm{OH}$, USA; ALS Association, Central \& Southern Ohio Chapters, Columbus, OH, USA; and ALS Association, Northern Ohio Chapter, Independence, $\mathrm{OH}, \mathrm{USA}$.

For initial diagnosis, patients attended ALS/neuromuscular clinics and underwent typical studies. For research purposes, the diagnosis was confirmed and classified according to the Awaji criteria as definite, probable, and possible ALS [25]. After completion of the 2-year index period, medical records were reviewed (when available) to update the diagnostic classification.

Upon identifying an eligible patient, clinic staff collected the age, gender, and zip code of patient's residence. For consenting patients, the clinic staff completed a full case report form that included the patient's unique clinic identifier; date of diagnosis; the Awaji classification; whether electromyography had been performed; whether the diagnosis was made by an ALS specialist, a general neurologist, or an internist/general practitioner; whether genetic testing had been done; patient's name and address at time of diagnosis; date of birth; gender; race/ethnicity; place of birth; 


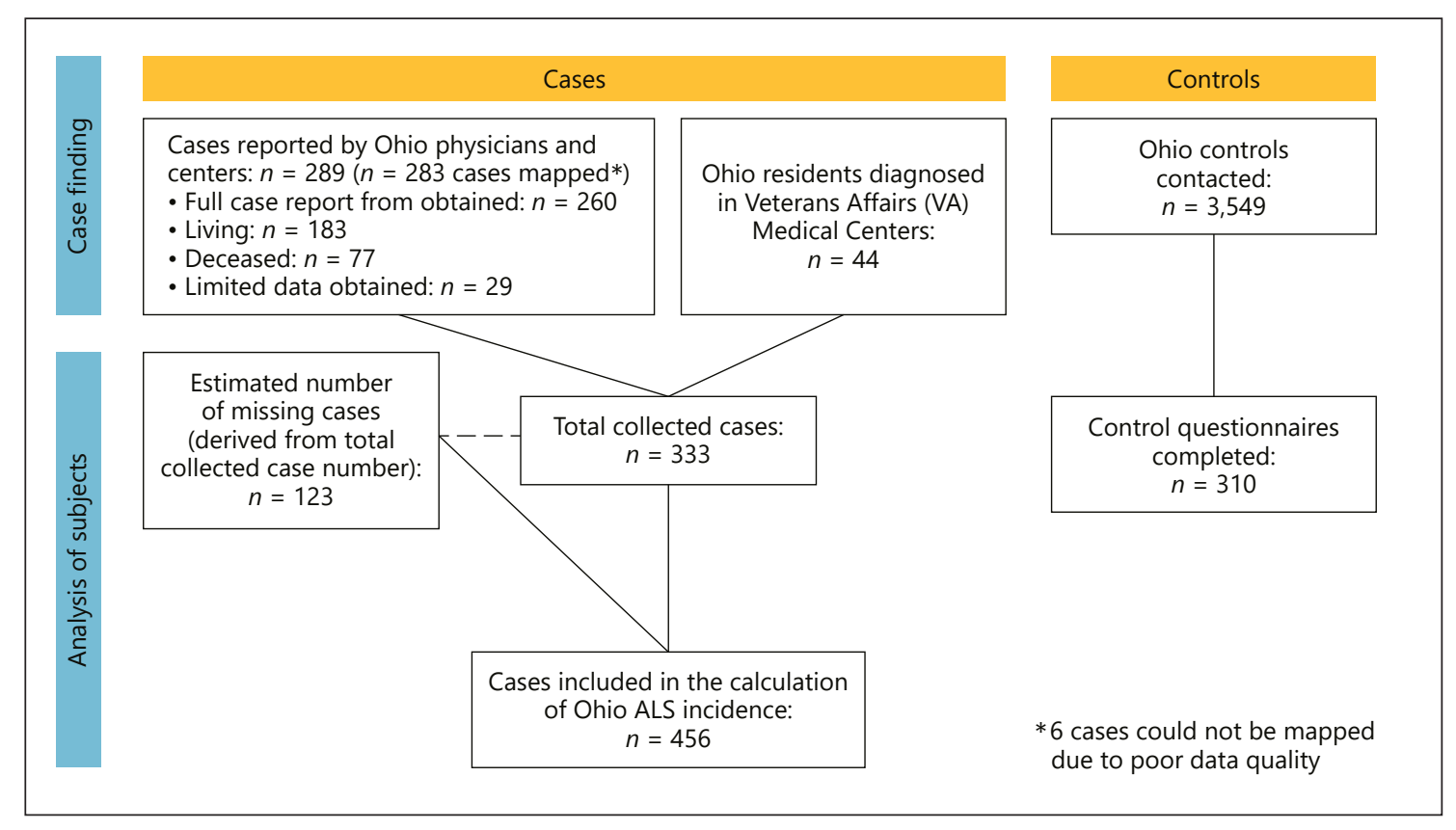

Fig. 1. Cohort diagram depicting the ascertainment of cases and controls collected and analyzed in this study. ALS, amyotrophic lateral sclerosis.

family history of ALS; whether patient had a diagnosis of dementia; smoking history and riluzole prescription. The patient's or family member's assertion about dementia was accepted; no formal testing was applied. Participating patients were also asked to complete a lifestyle questionnaire.

At the end of the study, medical records were reviewed to identify ALS patients who had died, in which case additional demographic information was extracted for the central database. The registry database was further reviewed in consultation with the reporting institution to eliminate any duplicate records of participants registered at $>1$ facility.

\section{Estimation of Underrecruitment of Cases ("Missing Cases")}

We were unable to trace every newly diagnosed case of ALS in Ohio during the index time window for at least 2 reasons: (1) not all centers/physicians developed collaborative agreements with the registry (although many patients from these centers were seen by Dr. Pioro) and (2) patients from some parts of Ohio may go to other states for their medical care. To address this underrecruitment problem, we developed a method to estimate the number of missing cases that we describe in detail elsewhere (manuscript in preparation).

In brief, the estimation method involves 4 steps. We applied this 4-step process to male cases and female cases separately in order to address the well-known male predominance in ALS. Step 1: calculate the crude rate for each county using the collected cases and the corresponding sex-specific county population. Step 2: select those counties whose crude rates are within $\mid z$-score $\mid<v$, where $v$ is a prespecified threshold. In this study we tested $v=0.5$. Upon applying the prespecified threshold, the selected counties are referred to as reference counties and are considered to have the normal situation in terms of case-population relationship. Step 3: run a Poisson regression using the data of reference counties to establish the case-population relationship. Step 4: use the established case-population relationship and county population value to estimate the expected case count for those counties whose crude rate is lower than that of the reference counties. If a county's expected case count is greater than the number of collected cases, the difference between the two represents an estimate of that county's number of "missing" cases. We used a Monte Carlo process to estimate the $95 \%$ confidence interval. Estimation of the number of missing cases was conducted using the $\mathrm{R}$ package, primarily for running the Poisson regression. All the other tabular calculations in the estimation were conducted using Excel.

Recruitment of a Cohort of Population-Based Control Subjects

Using the US Postal Service Delivery Sequence file licensed to Marketing Systems Group (Horsham, PA, USA), we identified population controls that were recruited by mail to complete the same lifestyle questionnaire as the ALS patients. The population sampling algorithm was deliberately skewed in age and gender to mirror the demographics of patients with ALS, which is more common in the 6th and 7th decades and among males.

\section{Results}

Total Number of ALS Cases in Ohio from 2016 to 2018

We collected 289 unique cases from collaborating sites with diagnoses meeting Awaji criteria of definite, probable, and possible ALS in the 2-year window of October 1, 2016, through September 30, 2018 (Fig. 1). Among the living ALS 


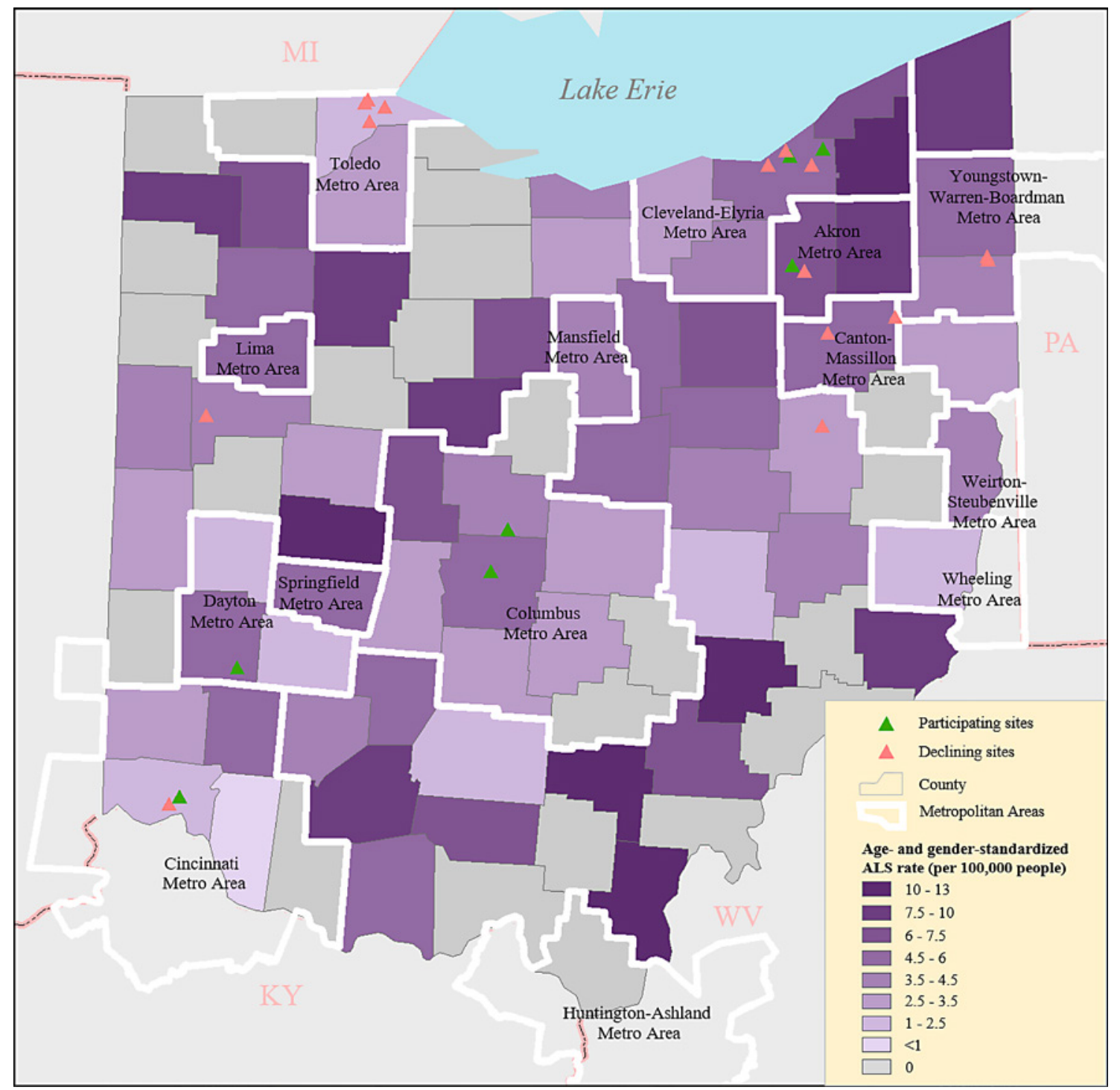

Fig. 2. Age- and gender-standardized ALS incidence rates in Ohio, based on collected data and 2016 countylevel demographic data for Ohio $(n=283)$. Darker shades of purple denote increasing ALS rates. No cases were reported from the gray-shaded counties. ALS, amyotrophic lateral sclerosis.

patients approached about the registry, $86 \%$ elected to submit a full case report form. We have limited reportable data for the remaining 29 cases (14\%), as well as the additional 44 cases counted from the VA system. Together, we identified a total of 333 unique ALS patients diagnosed among residents of Ohio in the 2-year time window. Based on 2016 postcensal population estimates, the general Ohio population $\geq 20$ years of age is $8,711,271$ [26]. We also collected epidemiological data on 310 population-based, random control subjects. Controls were sampled by mail from the general population and approximately $9 \%$ completed the same detailed questionnaire as the ALS patients $(n=310)$.

\section{Geographic Distribution of ALS Cases}

The observed distribution of age- and gender-adjusted ALS incidence was not uniform in all Ohio counties (Fig. 2). We hypothesize that patients in counties with low incidences were either not enrolled by centers/physicians or traveled to ALS centers in neighboring states to receive care. There were also counties with a high frequency of cases ("hot spots") that will be addressed in future studies.

Based on the statistical method outlined above and using $v=0.5$, we estimate that a total of 123 cases were "missing" from our recruitment effort (95\% confidence interval 95-160). This value was computed as the sum of 




Fig. 3. ALS cases collected from participating Ohio sites (green circles; $n=283$ ) and the estimated number of "missing" ALS cases (orange circles; $n=123$ ) in individual Ohio counties. ALS, amyotrophic lateral sclerosis.

male cases ( $n=70,95 \%$ confidence interval 50-97) and female cases ( $n=53,95 \%$ confidence interval $34-80$ ). The expected spatial distribution of these "missing" cases is shown in Figure 3.

\section{Incidence of ALS in Ohio in 2016-2018}

After incorporating the 123 estimated "missing" cases to the total "collected" case number of 333 , the "corrected" crude incidence was 1.96/100,000 patient-years (Table 1). The "corrected" crude incidence rates were 2.37 for males and 1.57 for females. The age- and gender-standardized incidence rate for Ohio was $1.71 / 100,000$ pa- tient-years [27]. Marin et al. [16] reported an age- and gender-standardized rate of 1.81 (95\% confidence interval 1.66-1.97) using 2010 US census data. The US 2010-standardized sex ratio of male to female incidence rates was 1.47 in Ohio and 1.41 worldwide [16] (Table 1).

\section{Characteristics of the Ohio ALS Population}

Table 2 shows the age and gender distribution of ALS cases identified for the registry. Based on collected cases, patients with ALS were more likely to be male and aged $60-69$ years ( $40 \%$ of males and $32 \%$ of females were in this age group). 
Table 1. Annual ALS incidence rates for Ohio compared to published rates

\begin{tabular}{lllll}
\hline & Crude & $\begin{array}{l}\text { Age, gender standardized, } \\
\text { all }\end{array}$ & $\begin{array}{l}\text { Age standardized, } \\
\text { male }\end{array}$ & $\begin{array}{l}\text { Age standardized, } \\
\text { female }\end{array}$ \\
\hline $\begin{array}{l}\text { Ohio 2016-2018 } \\
\text { Previously published rates [16] }\end{array}$ & $1.96 / 100,000^{*}$ & $1.71 / 100,000^{*}$ & $2.04 / 100,000^{*}$ & $1.39 / 100,000^{*}$ \\
$\quad$ Worldwide & & & & $1.47^{*}$ \\
$\quad \begin{array}{l}\text { Europe, North America, New } \\
\quad \text { Zealand }\end{array}$ & $1.75(1.55-1.96) / 100,000$ & $1.68(1.50-1.85) / 100,000$ & $1.96 / 100,000$ & $1.39 / 100,000$ \\
\end{tabular}

ALS, amyotrophic lateral sclerosis. *After the inclusion of "missed" cases.

Table 2. Age and gender of Ohio ALS Registry patients diagnosed in 2016-2018

\begin{tabular}{|c|c|c|c|c|c|c|}
\hline \multirow[t]{2}{*}{ Diagnosis age } & \multicolumn{2}{|l|}{ Female } & \multicolumn{2}{|l|}{ Male } & \multicolumn{2}{|l|}{ Overall } \\
\hline & missing & collected & missing & collected & missing & collected \\
\hline $20-49$ & 9.6 & 24 & 7.0 & 20 & 16.6 & 44 \\
\hline $50-59$ & 9.2 & 23 & 15.8 & 45 & 24.9 & 68 \\
\hline $60-69$ & 17.1 & 43 & 28.0 & 79 & 45.1 & 122 \\
\hline $70-79$ & 14.3 & 36 & 15.8 & 45 & 30.1 & 81 \\
\hline $80+$ & 2.8 & 7 & 3.5 & 10 & 6.3 & 17 \\
\hline Missing & na & 0 & na & 1 & na & 1 \\
\hline Total & 53 & 133 & 70 & 200 & 123 & 333 \\
\hline
\end{tabular}

ALS, amyotrophic lateral sclerosis.

Demographic data from ALS patients with completed case report forms, the sampled population controls, and the whole Ohio population $[26,28]$ are shown in Table 3. A positive family history of ALS was much more common in ALS patients (7.6\%), compared to sampled controls $(1.6 \%)$. The racial distribution of the groups was similar; $81 \%$ ALS patients reported white race compared to $83 \%$ of the sampled population controls and $85 \%$ of the Ohio population, although blacks were less frequent in the ALS patient group compared to the sampled controls.

As shown in Table 4, most patients in the Ohio Registry met Awaji criteria for definite (35\%) or probable (39\%) ALS. Dementia was rare, affecting approximately $4 \%$ of the patients. Riluzole had been prescribed to $62 \%$ of the ALS patients.

\section{Discussion/Conclusion}

The Ohio ALS Registry aimed to collect data on all patients newly diagnosed with ALS and living in Ohio during the 2-year index period (2016-2018). This effort is part of a larger project to identify epidemiological environmental risk factors in a state where the population has a history of high exposure to industrial and agricultural toxins and to water bodies with frequent harmful cyanobacterial blooms.

Because not all neurologists/centers in Ohio participated in this study, and because some ALS patients residing in Ohio receive their medical care outside the state, a number of patients were likely missed. To correct for this, we developed a modeling method to estimate the number of missed cases. We attempted to identify reference counties using a priori knowledge about the completeness of case recruitment. However, we were not able to assure a sufficient number of "reference" counties to build solid statistical models. We acknowledge that using an average of the rates observed in all 88 counties as the center point for our references is likely to underestimate the number of missing cases. However, we decided that for a rare disease like ALS, such a conservative strategy is more acceptable than an aggressive approach that would result in an overestimation of missing cases. The results of our approach qualitatively agreed with our expectations, with many "missed" cases in the counties around Toledo and in Cincinnati and few "missing" cases in the Cleveland, Columbus, and Dayton areas where we had strong recruitment (Fig. 3). 
Table 3. Characteristics of the Ohio ALS patients, controls, and the general population

\begin{tabular}{|c|c|c|c|}
\hline & $\begin{array}{l}\text { ALS case report forms } \\
(n=289)(\%)\end{array}$ & $\begin{array}{l}\text { Population controls } \\
(n=310)(\%)\end{array}$ & $\begin{array}{l}\text { Ohio population *,\# } \\
(n=8,711,271)(\%)\end{array}$ \\
\hline \multicolumn{4}{|l|}{ Age } \\
\hline $20-49$ & $38(13.1)$ & $44(14.2)$ & $4,415,962(50.7)$ \\
\hline $50-59$ & $64(22.1)$ & $158(51.0)$ & $1,645,763(18.9)$ \\
\hline $60-69$ & $110(38.1)$ & $82(26.5)$ & $1,406,905(16.2)$ \\
\hline $70-79$ & $66(22.8)$ & $20(6.5)$ & $757,386(8.7)$ \\
\hline $80+$ & $10(3.5)$ & $6(0.02)$ & $485,255(5.6)$ \\
\hline Missing & $1(0.3)$ & $0(0)$ & $0(0)$ \\
\hline \multicolumn{4}{|l|}{ Gender } \\
\hline Female & $131(45.3)$ & $89(28.7)$ & $4,506,022(51.7)$ \\
\hline Male & $158(54.7)$ & $221(71.3)$ & $4,205,249(48.3)$ \\
\hline \multicolumn{4}{|l|}{ Family history } \\
\hline No & $216(75.0)$ & $305(98.4)$ & na \\
\hline Yes & $22(7.6)$ & $5(1.6)$ & na \\
\hline Missing & $29(10.1)$ & $0(0)$ & na \\
\hline Do not know & $21(7.3)$ & $0(0)$ & na \\
\hline \multicolumn{4}{|l|}{ Race } \\
\hline White & $234(81.0)$ & $256(82.6)$ & 7,392,894 (84.9) \\
\hline Black & $10(3.5)$ & $25(8.1)$ & $1,077,772(12.4)$ \\
\hline Others & $6(2.1)$ & $11(3.5)$ & $240,605(2.8)$ \\
\hline Missing & $39(12.6)$ & $18(5.8)$ & $0(0)$ \\
\hline \multicolumn{4}{|l|}{ Smoking } \\
\hline Nonuser & $155(53.8)$ & $145(46.8)$ & $(51.3)$ \\
\hline Yes, current user & $32(11.1)$ & $38(12.3)$ & $(20.6)$ \\
\hline Yes, former user & $59(20.5)$ & $110(35.5)$ & $(25.4)$ \\
\hline Missing & $29(10.1)$ & $17(5.5)$ & $(2.7)$ \\
\hline Do not know & $13(4.5)$ & $0(0)$ & $(0)$ \\
\hline
\end{tabular}

ALS, amyotrophic lateral sclerosis. * 2016 Ohio age, gender, and race data obtained through the Ohio Department of Health [26]. Estimated prevalence of smoking status by age from the Ohio Behavioral Risk Factor Surveillance System (BRFSS), 2018 [28].

The Ohio ALS Registry is not alone in needing to assess and compensate for underrecruitment. Preux and colleagues [29] adopted a capture-recapture method to ascertain all ALS patients in Limousin, France, during 1994-1995. They analyzed the numbers of cases from 3 different data sources and then built statistical models to estimate the total number of cases. Their method was based on the assumption that the cases captured by each data source were a random sampling of all cases. In our situation however, the data sources include only a subset of Ohio hospitals and therefore is far from a random sample. Our method predicts the number of missing cases for each county, which is used to estimate the statewide total number, and more importantly, characterizes the spatial variation of the cases. In the future, we plan to compare our estimates to mortality statistics when they become available for this cohort. We are also aware that areas with small populations are more vulnerable to variations in incidence due to chance. Further research is required to address the impact of this small-area problem on the estimation of missing cases.

Based on our model, we estimate that we recruited $73 \%$ of the total ALS cases in Ohio during the index period, which is similar to the $50-70 \%$ completeness of case finding reported in the literature using capture-recapture methodology $[29,30]$. Adding the "missed" cases to the observed cases yielded a "corrected" crude incidence rate of 1.96/100,000 patient-years. For North America, Xu et al. [31] reported a crude incidence of 1.60 (95\% CI: 1.232.01). Our Ohio "corrected" age- and gender-standardized incidence rate was $1.71 / 100,000$ patient-years. This Ohio rate is comparable to the incidence rates reported by the National ALS Registry State and Metropolitan Area Surveillance programs in the USA $[18,32,33]$, though most of the National ALS Registry reports have concentrated on prevalence rates [17, 34]. Massachusetts 
Table 4. Clinical characteristics of the Ohio ALS Registry patients for whom we have case report forms

\begin{tabular}{|c|c|}
\hline & $n=289(\%)$ \\
\hline \multicolumn{2}{|l|}{ Awaji } \\
\hline Definite & $101(34.9)$ \\
\hline Probable & $113(39.1)$ \\
\hline Possible & $38(13.1)$ \\
\hline Missing & $34(11.8)$ \\
\hline Not classifiable & $3(1.0)$ \\
\hline \multicolumn{2}{|l|}{ Dementia } \\
\hline Yes, frontotemporal dementia & $9(3.1)$ \\
\hline Yes, others & $3(1.0)$ \\
\hline No & $243(84.4)$ \\
\hline Missing & $30(10.4)$ \\
\hline Do not know & $3(1.0)$ \\
\hline \multicolumn{2}{|l|}{ Riluzole } \\
\hline Yes & $179(61.9)$ \\
\hline No & $57(19.7)$ \\
\hline Missing & $44(15.2)$ \\
\hline Do not know & $9(3.1)$ \\
\hline \multicolumn{2}{|l|}{ Genetic testing } \\
\hline Yes & $64(22.1)$ \\
\hline No & $161(55.7)$ \\
\hline Missing & $29(10.0)$ \\
\hline Do not know & $35(12.1)$ \\
\hline \multicolumn{2}{|l|}{ Hospital location } \\
\hline Canton & $12(4.2)$ \\
\hline Centerville & $15(5.2)$ \\
\hline Cincinnati & $7(2.4)$ \\
\hline Cleveland & $161(55.7)$ \\
\hline Columbus & $77(26.6)$ \\
\hline Westerville & $13(4.5)$ \\
\hline Missing & $4(1.4)$ \\
\hline
\end{tabular}

ALS, amyotrophic lateral sclerosis.

is the only state in the USA with a mandatory ALS registry. The 2007-2011 age-adjusted, average annual incidence rate of 2.2/100,000 (range 2.0-2.5) patients was reported by the ALS Registry of Massachusetts [35]. We found a comparable age-adjusted Ohio incidence rate of 2.6. The age-adjusted Ohio rate appears higher than ageadjusted rates calculated for other US states, such as New Jersey (1.67) [13] and California (1.7) [36]. We posit these rates may reflect differences in monitoring systems and estimation methods, as well as potential local epidemiological or environmental factors.

In meta-analyses, ALS crude incidence rates have been reported to vary considerably in different countries and by race. The all-age global incidence of motor neuron disease is estimated to be 0.78 per 100,000 person-years [14], while the age-standardized rate for high-income North
America was calculated to be 2.3. The age- and genderstandardized rate reported in Europe, North America, and New Zealand is 1.81 [16]. Likewise, the standardized rate calculated for Ireland, the United Kingdom, and Italy was 1.7 (95\% confidence interval 1.6-1.9) [37]. Ageand sex-adjusted incidence rates for the United Kingdom for 2017 and 2018 diagnoses were slightly higher (2.07) [38], and those for Asia, South America, and the Caribbean are lower [16]. Across the world, many factors may explain these different rates, including genetic and ethnic/racial differences, variations in the healthcare systems, and underreporting [39], as well as environmental factors that might predispose individuals to ALS.

The ethnic/racial mix of patients in the Ohio ALS Registry was similar to that of patients collected by the US National ALS Registry, where $78.8 \%$ of cases were white in 2015 [17,33] compared to the Ohio ALS Registry where $81 \%$ were white. Whites have been reported to have nearly twice the ALS prevalence rates of blacks $[40,41]$. This difference is not due to longer survival bias because blacks have a slightly longer survival from the time of diagnosis $[42,43]$. Adjusted ALS mortality rates in Cuba varied by the ancestral group from 0.55 for the mixed population to 0.87 in blacks and up to 0.93 for whites [15]. There are many possible explanations for the racial/ethnic differences in ALS rates, including genetic factors, underreporting, limited access to healthcare, and death at an earlier age from other illnesses. We plan to explore these factors in future studies from the Ohio ALS Registry.

Reports of spatial clustering of ALS cases are controversial [19-24, 44-46]. However, such clusters may offer insight into environmental factors that possibly cause ALS, as well as be susceptible to mitigation. As such, the investigation of risk factors for ALS is one goal of the Ohio ALS Registry. We are currently collecting biosamples from ALS cases and controls to assess potential geneenvironment interactions.

We originally hypothesized that Ohio, with its extensive history of environmental pollution, application of pesticides, and cyanobacterial blooms, would have a higher incidence of ALS than other US states. However, our statelevel incidence rate estimates appear to be comparable to those observed in Massachusetts, which has the only mandatory ALS registry in the USA. Our findings reveal that some Ohio counties have considerably higher standardized incidence rates than others (up to 10-13 cases/100,000 patient-years). We are currently investigating the environmental ALS risk factors in these "hot spot" counties.

In a recent paper, de Jongh et al. [47] described a large analysis of the incidence, prevalence and geographical 
distribution of ALS cases in the Netherlands. Using a capture-recapture method, they estimated that they identified $73 \%$ of the total prevalent cases. The crude annual incidence was 2.64/100,000 patient-years, similar to findings in other western European studies. They found that the age- and sex-adjusted mortality rate of ALS increased by $14.1 \%$ over the last two decades as well as identified considerable regional variation in the distribution of ALS cases, with statistically significant relative risks ranging from 0.78 to 1.48 , compared to the national risk.

\section{Acknowledgements}

We thank the staff and study participants for making this work possible. We especially thank Amanda Haidet-Phillips of Muscular Dystrophy Association, Ohio; Mary Wheelock and Lisa Bruening of the ALSA Northern Ohio Chapter; Dawn Caraballo, Irys Caristo, and Charlotte Tse at the Section of ALS and Related Disorders, Cleveland Clinic; and the nurses and clinic staff at all the collaborating centers in Ohio. We thank Wendy Kaye for review of the manuscript.

\section{Statement of Ethics}

This study was approved by the Dartmouth-Hitchcock Medical Center IRB and by the IRB of institutions that did not defer to the Dartmouth-Hitchcock Medical Center IRB, including the VA Medical Center Research and Development Committee, White River Junction, VT. ALS cases from Ohio VA Medical Centers were counted from within the VA Informatics and Computing Infrastructure firewall. Patients were told about the Ohio ALS Registry, provided with printed information, and invited to take part in the study by signing an informed consent form approved by the relevant institutional review boards, or by verbal affirmation, approved by the relevant IRB.

\section{Conflict of Interest Statement}

The authors have no conflicts of interest to declare.

\section{Funding Sources}

This study was funded by a grant from the Centers for Disease Control and Prevention ATSDR 1R01TS000245.

\section{Author Contributions}

Angeline Andrew designed the study, maintained the database, supervised recruitment of population controls, analyzed the data, and wrote the manuscript. Erik Pioro helped design the study, supervised clinical care and enrollment of patients, and wrote the manuscript. Meifang Li performed the statistical analysis of missed cases and the mapping. Xun Shi designed the study, analyzed the data, provided the figures, and wrote the manuscript. Jiang Gui supervised the statistical analysis of missed cases. Elijah Stommel designed the study and supervised the Dartmouth-Hitchcock Medical Center team. Tanya Butt recruited participating institutions in Ohio and maintained the database. Daniel Peipert recruited participating institutions in Ohio and maintained the database. Patricia Henegan initiated recruitment of participating institutions in Ohio and maintained the database in the early part of the study. Maeve Tischbein maintained the database in the later part of the study and assisted in writing the manuscript. Pamela Cazzolli, John Novak, Adam Quick, Doug Pugar, Komal Sawlani, Bahir Katirji, and Todd Hayes recruited patients and assisted in writing the manuscript. Kevin Horton and Paul Mehta advised on the design of the study and assisted in writing the manuscript. Walter Bradley designed the study, coordinated the research team, analyzed the data, and wrote the manuscript.

\section{References}

1 Chiò A, Mora G, Calvo A, Mazzini L, Bottacchi E, Mutani R. Epidemiology of ALS in Italy: a 10-year prospective population-based study. Neurology. 2009 Feb 24;72(8):725-31.

2 Chia R, Chiò A, Traynor BJ. Novel genes associated with amyotrophic lateral sclerosis: diagnostic and clinical implications. Lancet Neurol. 2018 Jan;17(1):94-102.

3 Ingre C, Roos PM, Piehl F, Kamel F, Fang F. Risk factors for amyotrophic lateral sclerosis. Clin Epidemiol. 2015 Feb 12;7:181-93.

4 Leblond CS, Kaneb HM, Dion PA, Rouleau GA. Dissection of genetic factors associated with amyotrophic lateral sclerosis. Exp Neurol. 2014 Dec;262 Pt B:91-101.

5 Renton AE, Chiò A, Traynor BJ. State of play in amyotrophic lateral sclerosis genetics. Nat Neurosci. 2014 Jan;17(1):17-23.
6 Marangi G, Traynor BJ. Genetic causes of amyotrophic lateral sclerosis: new genetic analysis methodologies entailing new opportunities and challenges. Brain Res. 2015 May 14;1607:75-93.

7 Pang SY, Teo KC, Hsu JS, Chang RS, Li M, Sham PC, et al. The role of gene variants in the pathogenesis of neurodegenerative disorders as revealed by next generation sequencing studies: a review. Transl Neurodegener. 2017 Oct 6;6:27.

8 Taskesen E, Mishra A, van der Sluis S, Ferrari R, Veldink JH, van Es MA, et al. Susceptible genes and disease mechanisms identified in frontotemporal dementia and frontotemporal dementia with amyotrophic lateral sclerosis by DNA-methylation and GWAS. Sci Rep. 2017 Aug 21;7(1):8899.
9 Bradley WG, Andrew AS, Traynor BJ, Chiò A Butt TH, Stommel EW. Gene-environmenttime interactions in neurodegenerative diseases: hypotheses and research approaches. Ann Neurosci. 2018 Dec;25(4):261-7.

10 Al-Chalabi A, Calvo A, Chio A, Colville S, Ellis CM, Hardiman O, et al. Analysis of amyotrophic lateral sclerosis as a multistep process: a population-based modelling study. Lancet Neurol. 2014 Nov;13(11):1108-13.

11 Chiò A, Mazzini L, D’Alfonso S, Corrado L, Canosa A, Moglia C, et al. The multistep hypothesis of ALS revisited: the role of genetic mutations. Neurology. 2018 Aug 14;91(7):e635-e42.

12 Mehta P, Antao V, Kaye W, Sanchez M, Williamson D, Bryan L, et al. Prevalence of amyotrophic lateral sclerosis: United States, 20102011. MMWR Suppl. 2014 Jul 25;63(7):1-14. 
13 Jordan H, Fagliano J, Rechtman L, Lefkowitz D, Kaye W. Population-based surveillance of amyotrophic lateral sclerosis in New Jersey, 20092011. Neuroepidemiology. 2014;43(1):49-56.

14 GBD 2016 Motor Neuron Disease Collaborators. Global, regional, and national burden of motor neuron diseases 1990-2016: a systematic analysis for the Global Burden of Disease Study 2016. Lancet Neurol. 2018 Dec;17(12): 1083-97.

15 Zaldivar T, Gutierrez J, Lara G, Carbonara M, Logroscino G, Hardiman O. Reduced frequency of ALS in an ethnically mixed population: a population-based mortality study. Neurology. 2009 May 12;72(19):1640-5.

16 Marin B, Boumédiene F, Logroscino G, Couratier $\mathrm{P}, \mathrm{Babron} \mathrm{MC}$, Leutenegger $\mathrm{AL}$, et al. Variation in worldwide incidence of amyotrophic lateral sclerosis: a meta-analysis. Int $J$ Epidemiol. 2017 Feb;46(1):57-74.

17 Mehta P, Kaye W, Raymond J, Punjani R, Larson T, Cohen J, et al. Prevalence of amyotrophic lateral sclerosis: United States, 2015. MMWR Morb Mortal Wkly Rep. 2018 Nov 23;67(46):1285-9.

18 Wagner L, Rechtman L, Jordan H, Ritsick M, Sanchez M, Sorenson E, et al. State and metropolitan area-based amyotrophic lateral sclerosis (ALS) surveillance. Amyotroph Lateral Scler Frontotemporal Degener. 2015; 17(1-2):128-34.

19 Caller TA, Doolin JW, Haney JF, Murby AJ, West KG, Farrar HE, et al. A cluster of amyotrophic lateral sclerosis in New Hampshire: a possible role for toxic cyanobacteria blooms. Amyotroph Lateral Scler. 2009;10(Suppl 2): 101-8.

20 Caller TA, Field NC, Chipman JW, Shi X, Harris BT, Stommel EW. Spatial clustering of amyotrophic lateral sclerosis and the potential role of BMAA. Amyotroph Lateral Scler. 2012 Jan;13(1):25-32.

21 Caller TA, Chipman JW, Field NC, Stommel EW. Spatial analysis of amyotrophic lateral sclerosis in Northern New England, USA, 19972009. Muscle Nerve. 2013 Aug;48(2):235-41.

22 Masseret E, Banack S, Boumédiène F, Abadie E, Brient L, Pernet F, et al. Dietary BMAA exposure in an amyotrophic lateral sclerosis cluster from Southern France. PLoS One. 2013;8(12):e83406.

23 Torbick N, Hession S, Stommel E, Caller T. Mapping amyotrophic lateral sclerosis lake risk factors across northern New England. Int I Health Geogr. 2014 Jan;13:1.

24 Torbick N, Ziniti B, Stommel E, Linder E, Andrew A, Caller T, et al. Assessing cyanobacterial harmful algal blooms as risk factors for amyotrophic lateral sclerosis. Neurotox Res. 2018 Jan;33(1):199-212.
25 Costa J, Swash M, de Carvalho M. Awaji criteria for the diagnosis of amyotrophic lateral sclerosis: a systematic review. Arch Neurol. 2012 Nov;69(11):1410-6.

26 Ohio Department of Health [Internet]. Population data for calculating rates [cited 2020 July 30]. Available from: http://publicapps. odh.ohio.gov/EDW/DataBrowser/Browse/ Population.

27 United States Census Bureau [Internet]. 2010 census data products: United States. [cited 2020 July 30]. Available from: https://www. census.gov/population/www/cen2010/ glance/.

28 Ohio 2018 BRFSS Annual Report. Chronic disease epidemiology and evaluation section, office of health improvement and wellness, Ohio department of health. 2020.

29 Preux PM, Druet-Cabanac M, Couratier P, Debrock C, Truong T, Marcharia W, et al. Estimation of the amyotrophic lateral sclerosis incidence by capture-recapture method in the Limousin region of France. J Clin Epidemiol. 2000 Oct;53(10):1025-9.

30 Nelson LM, Topol B, Kaye W, Williamson D, Horton DK, Mehta P, et al. Estimation of the prevalence of amyotrophic lateral sclerosis in the United States using national administrative healthcare data from 2002 to 2004 and capture-recapture methodology. Neuroepidemiology. 2018;51(3-4):149-57.

31 Xu L, Liu T, Liu L, Yao X, Chen L, Fan D, et al. Global variation in prevalence and incidence of amyotrophic lateral sclerosis: a systematic review and meta-analysis. J Neurol. 2020 Apr;267(4):944-53.

32 Freer C, Hylton T, Jordan HM, Kaye WE, Singh S, Huang Y. Results of Florida's amyotrophic lateral sclerosis surveillance project, 2009-2011. BMJ Open. 2015 Apr 21;5(4): e007359.

33 Centers for Disease Control and Prevention [Internet]. State-metro ALS surveillance. [cited 2020 July 30]. Available from: https:// www.cdc.gov/als/ALSStateMetro.html.

34 Mehta P, Kaye W, Raymond J, Wu R, Larson $\mathrm{T}$, Punjani R, et al. Prevalence of amyotrophic lateral sclerosis: United States, 2014. MMWR Morb Mortal Wkly Rep. 2018 Feb 23;67(7): 216-8.

35 Health MDoP. ALS 2007-2011 data brief data brief: the Arego Paul Cellucci amyotrophic lateral sclerosis (ALS) registry of Massachusetts. 2016.

36 Valle J, Roberts E, Paulukonis S, Collins N, English P, Kaye W. Epidemiology and surveillance of amyotrophic lateral sclerosis in two large metropolitan areas in California. Amyotroph Lateral Scler Frontotemporal Degener. 2015 Jun;16(3-4):209-15.
37 Logroscino G, Traynor BJ, Hardiman O, Chiò A, Mitchell D, Swingler RJ, et al. Incidence of amyotrophic lateral sclerosis in Europe. J Neurol Neurosurg Psychiatry. 2010 Apr; 81(4):385-90

38 Opie-Martin S, Ossher L, Bredin A, Kulka A, Pearce N, Talbot K, et al. Motor neuron disease register for England, Wales and Northern Ireland-an analysis of incidence in England. Amyotroph Lateral Scler Frontotemporal Degener. 2020 Sep 17:1-8

39 Logroscino G, Piccininni M. Amyotrophic lateral sclerosis descriptive epidemiology: the origin of geographic difference. Neuroepidemiology. 2019;52(1-2):93-103.

40 Rechtman L, Jordan H, Wagner L, Horton DK, Kaye W. Racial and ethnic differences among amyotrophic lateral sclerosis cases in the United States. Amyotroph Lateral Scler Frontotemporal Degener. 2015 Mar;16(1-2): 65-71.

41 Mehta P, Kaye W, Bryan L, Larson T, Copeland T, Wu J, et al. Prevalence of amyotrophic lateral sclerosis: United States, 2012-2013. MMWR Surveill Summ. 2016 Aug 5;65(8): 1-12.

42 Quadri M, Cossu G, Saddi V, Simons EJ, Murgia D, Melis M, et al. Broadening the phenotype of TARDBP mutations: the TARDBP Ala382Thr mutation and Parkinson's disease in Sardinia. Neurogenetics. 2011 Aug;12(3): 203-9.

43 Gundogdu B, Al-Lahham T, Kadlubar F, Spencer H, Rudnicki SA. Racial differences in motor neuron disease. Amyotroph Lateral Scler Frontotemporal Degener. 2014 Mar; 15(1-2):114-8.

44 Rooney J, Heverin M, Vajda A, Crampsie A, Tobin K, Byrne S, et al. An exploratory spatial analysis of ALS incidence in Ireland over 17.5 years (1995-July 2013). PLoS One. 2014 May; 9(5):e96556.

45 Bradley WG, Stommel EW, Shi X, Torbick NM, Caller TA, Sabel CE, et al. Spatial cluster analysis of population amyotrophic lateral sclerosis risk in Ireland. Neurology. 2015 Nov; 85(20):1822-3.

46 Rooney J, Vajda A, Heverin M, Elamin M, Crampsie A, McLaughlin R, et al. Spatial cluster analysis of population amyotrophic lateral sclerosis risk in Ireland. Neurology. 2015 Apr; 84(15):1537-44.

47 de Jongh AD, Ruben P, van Eijk A, Peters SM, van Es MA, Horemans A, et al. Incidence, prevalence, and geographical clustering of motor neuron disease in the Netherlands. Neurology. 2021;96:e1227-e1236. 